\title{
¿Juicio legítimo o golpe de Estado encubierto? El impeachment a la Presidenta de la República Federal de Brasil, Dilma Rousseff ${ }^{*}$
}

\section{¿Legitimate trial or covert coup? The impeachment to the President of the Brazilian Federal Republic, Dilma Rousseff}

RESUMEN

La dimisión forzada de Dilma Rousseff ha provocado un seísmo institucional cuya profundidad y consecuencias precisan una evaluación reflexiva. Este hecho -la remoción efectiva de la ya expresidenta- se ha llevado a cabo utilizando el mecanismo de exigencia de responsabilidad característico del sistema presidencialista: el impeachment. El presente artículo evalúa -utilizando un enfoque interdisciplinario de ciencia política y derecho- si eran suficientes los motivos esgrimidos para deponer a la presidenta o si, por el contrario, se está ante un atentado contra el mandato soberano del cuerpo electoral que ha supuesto la remoción ilegal de una presidenta elegida por 54 millones de ciudadanos.

PALABRAS CLAVE

Impeachment, democracia, crisis institucional, neoliberalismo, golpe de Estado.

Posdoctor y doctor en Derecho por la Pontificia Universidade Católica do Rio Grande do Sul (PUCRS). Profesor de Derecho Constitucional de la Facultad de Ciencias Jurídicas, Económicas y Administrativas de la Universidad Católica de Temuco (UCT), Temuco, Chile. Contacto: dalmagro@uct.cl

Trabajo realizado en el marco del Proyecto de Investigación de Excelencia I+D “Democracia y participación política: hacia una redefinición de la ciudadanía democrática" (DER201566324-P), financiado por el Ministerio de Economía y Competitividad y por la Unión Europea mediante los Fondos Feder.

Recibido el 23 de agosto de 2017, aprobado el 4 de abril de 2018.

Para citar el artículo: Almagro CASTRO, D. ¿Juicio legítimo o golpe de Estado encubierto? El impeachment a la Presidenta de la República Federal Brasileña, Dilma Rousseff. En Revista Derecho del Estado. N..$^{\circ}$ 42, enero-abril de 2019, pp. 25-50.

DOI: https://doi.org/10.18601/01229893.n42.02 
ABSTRACT

The involuntary resignation of the first women elected president in Brazil have had negative consequences for the desirable institutional strengthening of the brazilian democracy in such a profound way that needs a reflexive evaluation. This issue - the real overthrowing of the former president - is have been made by using the main responsibility mechanism established in the presidentialism system: the impeachment. The current article defines - by taking into consideration an interdisciplinary method founded on the Political Science as well as the Law science - if there were enough reason for the deposition of the prime minister or, on the contrary, it has meant a violation of the sovereign mandate given by the electorate, supposing the illegitimate removal of a president elected by fifty-four million citizens.

KEYWORDS

Impeachment, democracy, institutional crisis, neoliberalism, coup.

SUMARIO

1. A modo de breve introducción: el porqué de un enfoque interdisciplinario. 2. Un tiempo de enorme polarización política en Brasil: los antecedentes sociopolíticos del impeachment. 3. El juicio de impeachment en la Constitución Federal brasileña de 1988: características esenciales y finalidad. 4. Crónica de un impeachment ¿legítimo?: una revisión de los hechos y los argumentos de derecho sin olvidar el precedente Collor de Mello. Conclusiones. Referencias.

1. A MODO DE BREVE INTRODUCCIÓN: EL PORQUÉ DE UN ENFOQUE INTERDISCIPLINARIO

La destitución forzosa, en agosto de 2016, de la primera presidenta de la República Federal brasileña, Dilma Rousseff, ha supuesto, entre otros efectos que aquí se analizan, la alteración de la normalidad institucional resultante de las últimas elecciones a la Presidencia de la República celebradas en octubre de 2014. Se está ante un acontecimiento cuya trascendencia cabe medir, en lo que aquí interesa destacar, por la intensa labor que la doctrina brasileña viene desarrollando desde aquel entonces. Los trabajos de investigación al respecto se han enfocado en el estudio de los antecedentes, causas y consecuencias que este episodio de la política nacional viene provocando en el normal funcionamiento de las instituciones estatales y, por extensión, en la vida de los ciudadanos. Dicho en términos directos, se han concentrado en la manera como está afectando la convivencia interinstitucional y democrática. 
La lectura de la producción doctrinal permite observar la preferencia por el uso de dos enfoques netamente diferenciados: el politológico, centrado en los incentivos y los costes que motivaron el uso del impeachment por parte de la oposición; y el jurídico, enfocado en el análisis de las características y la procedencia jurídica de la activación del impeachment.

Partiendo de este hecho -la escasa o nula interacción entre ambos enfoques-, este artículo propone un diálogo interdisciplinario con el objeto de contextualizar y comprender el marco institucional brasileño y las motivaciones políticas que sirvieron a la oposición para justificar el uso del impeachment. La complejidad del contexto socio-político, las características propias del fisiologismo institucional brasileño y la intrincada aritmética parlamentaria resultante de las elecciones de 2014 fueron factores que incidieron notablemente en la puesta en marcha de este mecanismo de responsabilización.

Este ejercicio se completa con el análisis netamente jurídico de la naturaleza, características y consecuencias del mecanismo de impeachment consagrado en los artículos 85 y 86 de la Constitución Federal de 1988. El objetivo de este estudio es doble: a) demostrar la inconsistencia de los argumentos jurídicos utilizados durante el proceso de impeachment, y b) sugerir una tesis sobre el verdadero motivo de la caída de la presidenta Rousseff: la aprobación de la "Proposta de Emenda Constitucional 241" (en adelante, PEC 241) en unos términos y con unas consecuencias sociales difícilmente justificables. Sin embargo, es mejor no adelantarse a los acontecimientos y comenzar por donde hay que comenzar.

\section{UN TIEMPO DE ENORME POLARIZACIÓN POLÍTICA EN BRASIL:}

LOS ANTECEDENTES SOCIO-POLÍTICOS DEL IMPEACHMENT

La investidura de Dilma Rousseff en 2011 dio inicio a un escrutinio político y mediático sin precedentes en la democracia brasileña. Por primera vez una mujer con un perfil reconocido de negociadora inflexible y gestora eficiente -construcción facilitada por su pasado de destacada activista política contra la dictadura y por su formación como economista- se situaba a la cabeza del poder ejecutivo.

Una de las banderas electorales de su primer mandato sería la lucha contra los desorbitados intereses de la deuda pública brasileña, la tasa Selic, la más elevada del mundo occidental y que limitaba en buena medida la implementación de políticas públicas de inclusión y combate de la desigualdad. Estas acciones, obviamente, provocarían la reacción desairada de la banca y el capital financiero ${ }^{1}$.

1 Datos disponibles en: http://www.valor.com.br/brasil/2821356/dilma-volta-pressionarbancos-por-queda-das-taxas-de-juros; http://economia estadao.com.br/noticias/geral,dilma-querbaixar-taxa-selic-a-9-no-ano-que-vem-imp-,780158. 
El otro gran frente de protesta social serían las "Revoltas de Junho" de $2013^{[2]}$. Este movimiento, apartidario y transversal, se hizo notar a lo largo y ancho del país reclamando la priorización del gasto público en la modernización de las infraestructuras sanitarias y educativas. Su otra bandera, no menos importante, fue la puesta en marcha de una reforma política que supusiera un freno a los insoportables índices de corrupción política que mermaban el progreso de Brasil $^{3}$. Las marchas de junio, convenientemente manipuladas por determinados sectores de la opinión mediática y política, darían paso al ataque sistemático contra la acción política del gobierno federal y su imagen electoral; una situación de acoso y derribo que alcanzaría su clímax con la victoria final en el proceso de impeachment ${ }^{4}$.

La situación se complicaría aún más durante el año 2014. En primer lugar, en marzo de 2014 se produciría un hecho que añadiría mayor polarización social y política entre partidarios y detractores del impeachment: la publicación de la operación de la Policía Federal de Curitiba conocida como operación Lava Jato. En escasos meses iba a adquirir la condición de mayor escándalo de corrupción de la democracia brasileña, consistiendo, en esencia, en el desvío sistemático de cantidades astronómicas -se habla de cifras superiores a los 2.500 millones de dólares- procedentes de la compañía estatal Petrobras para, en lo que aquí interesa destacar, fomentar la financiación irregular de todos los partidos políticos que componen el arco parlamentario brasileño, con especial incidencia en el "Partido dos Trabalhadores" (en adelante, PT), el "Partido Socialista Democrático Brasileiro" (en adelante, PSDB) y el "Partido Progresista" (en adelante, PP) ${ }^{5}$.

En segundo lugar, aparecerían movimientos sociales apartidarios que, como el "Movimento Brasil Livre" (en adelante, MBL), tendrían por bandera la reivindicación del impeachment contra la presidenta. Este movimiento, supuestamente apartidario, contaría con financiación directa por parte de los principales partidos de la oposición igualmente pro-impeachment: el PSDB y el "Partido do Movimento Democrático Brasileiro" (en adelante, PMDB).

En este convulso escenario se produciría, a finales de 2014, la reelección de la mandataria por un margen estrechísimo de votos -el 51,6\% de los votos válidamente emitidos-. Por otra parte, la exigua mayoría parlamentaria de su partido en el Congreso Nacional (en adelante, $\mathrm{CN}$ ) condicionaría fuertemente

2 Paulani, L. M. Uma ponte para o abismo. En Jinkins, I. et al. Por que gritamos golpe? São Paulo: Boitempo, 2016, 73.

3 Nobre, M. Choque de democracia. As razoes da revolta. São Paulo: Companhia das Letras, 2013, 14 ss.; ReIs, M. O gigante acordado. São Paulo: Leya, 2013, 37 ss.

4 Souza, J. A radiografia do golpe. São Paulo: Leya, 2016, 87.

5 Para una consideración de las principales variables del caso Lava Jato véase: https:// internacional.elpais.com/internacional/2016/03/04/actualidad/1457087312_930018.html.

6 Véase: http://www1.folha.uol.com.br/poder/2016/05/1775543-audios-mostram-quepartidos-financiaram-mbl-em-atos-pro-impeachment.shtml 
su margen de maniobra y la haría depender en mayor medida de su socio principal de gobierno, el $\mathrm{PMDB}^{7}$.

Este partido -que en sus inicios sería la oposición al partido sustento de la dictadura militar, ARENA- ha completado un cambio fisiológico sin precedentes durante la restauración de la democracia, hasta el punto de adquirir la fisonomía propia de un partido cartel, únicamente interesado en adquirir y conservar cuotas de poder en atención a su representatividad parlamentaria ${ }^{8}$. Los resultados electorales y la idiosincrasia del PMDB acabarían llevando hasta límites insustentables la inestabilidad propia del presidencialismo de coalición brasileño9 .

El escenario del segundo periodo del gobierno Rousseff se asemejaba en mucho a la tormenta política perfecta: una base parlamentaria débil y dependiente principalmente del $\mathrm{PMDB}$, tan cicatero como volátil en su apoyo parlamentario; un escenario económico desfavorable con la inflación y el alza incontenible del dólar; movimientos sociales pro-impeachment como el antedicho MBL; y, no menos relevante, varios escándalos de corrupción simultáneos que salpicaban a la práctica totalidad de la cúpula dirigente del PT y a los partidos de la base gubernamental ${ }^{10}$.

En marzo de 2015, el PSDB y los medios de información asociados al electorado conservador -con el semanario político Veja, la Cadena $O$ Globo y el periódico A Folha de São Paulo a la cabeza- comenzaron un ciclo de movilización para exigir la puesta en marcha del juicio de impeachment ${ }^{11}$. Con el fin de la corrupción como argumento, los medios señalados dirigieron su atención prioritariamente hacia el PT, difuminando o directamente olvidando la corrupción en el PP, el PSDB y el $\mathrm{PMDB}^{12}$.

7 La composición del Congresso Nacional tras las elecciones de 2014 puede consultarse en: http://www1.folha.uol.com.br/infograficos/2014/10/117558-como-fica-o-congressoem-2015.shtml

8 Floriano Ribeiro, P. El modelo de partido cartel y el sistema de partidos de Brasil. En Revista de Ciencia Política. Vol. 33, n. ${ }^{\circ}$ 3, 2013, 607 ss. Sobre el papel del PMDB en la dictadura -reconocido con las siglas MDB- véase AlmAGRo CASTRo, D. Los partidos políticos en la historia constitucional brasileña. En Historia Constitucional. N. . 16, 2015, 264-267.

9 Ribeiro Gatto Cardoso, Y. y Bellan Rodrigues De Souza, R. Dilma, uma "presidente fora de si": o impeachment como um proceso patriarcal, sexista e midiático. En Revista Pauta Geral. Vol. 3, n. ${ }^{\circ}$ 2, 2016, 45-66.

10 Meneguelli, G. y Ferré-Pavia, C. Apología de la polémica como modalidad argumentativa: el conflicto público en Brasil en las protestas de 2015. En Revista de Estudios Culturales de la Universitat Jaume I. Vol. XvI, 2016, 57-58.

11 De Mello Brandao Tavares, F. et al. Um golpe anunciado: Lula, Dilma e o discurso pro-impeachment na Revista Veja. En Revista Pauta Geral. Estudos em Jornalismo. Vol. 3 , n. ${ }^{\circ}$ 2, 2016, 20-44; sobre las diferencias de tratamiento mediático de las manifestaciones a favor y contra del impeachment, véase Goncalves De OliveIRA, H. M. Retrato das manifestações de rua no processo de impeachment da Presidenta Dilma Rousseff: a construção da opinião pública pela mídia privada brasileira. En Revista Pauta Geral. Estudos em Jornalismo. Vol. 3, n. ${ }^{\circ} 2$, 2016, 83 ss.

12 Navarro, P. A. Volantazo en Brasil. En Los Dosieres del Siglo. N. ․ 1156, 2016, 26. 
Las razones para la puesta en marcha del impeachment esgrimidas por la oposición y los medios de comunicación afines se pueden resumir como sigue: a) el grave descontento de las clases medias-alta con la situación económica; b) el resentimiento del partido de la oposición por su cuarta derrota electoral consecutiva; c) la continuidad en política de un "criminal contumaz" como "Lula" y la incompetencia en la gestión de su sucesora; d) la crítica a los avances sociales y políticos de los sectores populares ${ }^{13}$. La combinación de estos cuatro elementos provocó una seria amenaza al sistema de creencias de la democracia, con un grado de violencia discursiva de los partidarios del impeachment hasta entonces desconocido.

La realidad es que el gobierno de la presidenta Rousseff ya mostraba signos evidentes de agotamiento en 2015, sin descartar graves errores de gestión propios $^{14}$. Sus aliados en el gobierno y en el CN le estaban retirando el apoyo parlamentario, sabedores de las posibles ganancias derivadas de un proceso de impeachment. El premio final sería la asunción de la Presidencia por el candidato del PMDB y vicepresidente del gobierno, Michel Temer.

Por otra parte, instituciones como el poder judicial -con el Supremo Tribunal Federal a la cabeza (en adelante, STF) - y la Policía Federal (en adelante, $\mathrm{PF}$ ) se encontraban inmersos en un grado de polarización partidaria sin precedentes, un hecho que en poco o nada contribuía a la recuperación de la normalidad institucional. En este sentido, adquiriría su cuota de protagonismo el magistrado encargado de la operación Lava Jato, Sergio Moro, quien entre otras acciones llamativas haría caso omiso de las acusaciones vertidas por la Policía Federal y por diferentes testigos contra los principales instigadores del impeachment: el presidente de la Cámara de los Diputados (en adelante, CD), Eduardo Cunha, y el candidato a la Presidencia Aécio Neves, líder del $\mathrm{PSDB}^{15}$. Ambos dirigentes políticos estaban acusados de participar directamente y en mayor número de ocasiones en dicha operación que la propia presidenta Rousseff ${ }^{16}$.

En párrafos precedentes se anticipó uno de los objetivos reales de su caída: dejar sin efecto conquistas sociales y derechos de los trabajadores, en favor de políticas de corte neolibera ${ }^{17}$. En este sentido, cabe destacar las declaraciones realizadas por el presidente interino Michel Temer poco tiempo después de asumir la Presidencia y según las cuales "[sería] preciso rescatar la imagen y credibilidad de Brasil en el concierto interno e internacional para

13 Luiz Callai, J. O que acontece no Brasil? En Revista de Didáticas Específicas. N. ${ }^{\circ} 14,2016,176-180$.

14 Ibíd.

15 Souza. A radiografia do golpe, cit., 119.

16 Navarro. Volantazo en Brasil, cit., 26.

17 PaUlani, L. M. Uma ponte para o abismo. En JinKINGs et al. (eds). Por que gritamos golpe?, cit., 75 . 
que los empresarios y trabajadores se entusiasmen y se retome la seguridad de las inversiones" 18 .

El giro liberal en materia económica y el recorte de derechos sociales, laborales y previsionales se materializaría meses más tarde en el proyecto de reforma constitucional avanzado en la parte introductoria: la PEC 241. Su aprobación definitiva ha supuesto, entre otras medidas devastadoras para la clase media trabajadora, la contención del gasto público en educación, sanidad y previsión social por espacio de veinte años. En este afán reformador no se ha contemplado, muy por el contrario, medida alguna que afecte al pago de los intereses de la deuda pública brasileña, la ya recordada tasa Selic ${ }^{19}$.

Aun a riesgo de anticipar algunas conclusiones del presente artículo, puede afirmarse tranquilamente que la destitución de Dilma Rousseff no ha traído consigo la recomposición y estabilidad de las instituciones y la vuelta del crecimiento económico que auspiciaban sus impulsores. Al contrario: las instituciones políticas brasileñas y la sociedad en su conjunto atraviesan una situación de crisis monumental que ha terminado por interrumpir nuevamente los ideales de progreso e integración social en Brasil ${ }^{20}$.

De igual forma, las últimas noticias sobre la situación procesal de los instigadores del impeachment arrojan serias dudas sobre la idoneidad moral de quienes pusieron en marcha un mecanismo que, con todo y sus innegables beneficios, es igualmente susceptible de generar situaciones de estrés institucional. En el marco de la operación Lava Jato, el líder político del PSDB y senador, Aécio Neves, ha sido suspendido temporalmente de su cargo, por su participación directa en el cobro de comisiones por valor de 2 millones de reales ${ }^{21}$; Renan Calheiros, presidente del Senado Federal durante la tramitación del impeachment en el mismo, ha sido definitivamente apartado de la presidencia de la Cámara Alta ${ }^{22}$; el presidente de la CD, Eduardo Cunha, cumple condena de 15 años por su participación directa en el caso Lava $J{ }{ }^{23}{ }^{23}$. Cierra el círculo el presidente Michel Temer, formalmente acusado

18 Navarro. Volantazo en Brasil, cit., 24 ss.

19 Costa, G. O desmonte do Estado. En Jinkings et al. (eds.), Por que gritamos golpe?, cit., 11; ALVES, G. A PEC 241, a contrarreforma neoliberal e a tragédia de Prometeu. Disponible en: https://blogdaboitempo.com.br/2016/10/19/a-pec-241-a-contra-reforma-neoliberal-e-atragedia-de prometeu/ (Consultado el 10 de agosto de 2017).

20 Braz, M. O golpe nas ilusões democráticas e a ascensão do conservadorismo reacionário. En Serviço Sociológico de São Paulo. N. ${ }^{\circ}$ 128, 2017, 88.

21 Datos disponibles en: https://noticias.uol.com.br/politica/ultimas-noticias/2017/06/30/ ministro-do-stf-autoriza-aecio-a-retomar-mandato-no-senado.htm. (Consultado el 10 de agosto de 2017).

22 Datos disponibles en: http://www.bbc.com/portuguese/brasil-38806052 (Consultado el 10 de agosto de 2017).

23 Datos disponibles en: http://g1.globo.com/pr/parana/noticia/eduardo-cunha-econdenador-a-15-anos-de-reclusao-por-tres-crimes-na-lava-jato.ghtml (Consultado el 10 de agosto de 2017). 
de corrupción y cuyo futuro como máximo mandatario del Ejecutivo ha sido objeto de reciente pronunciamiento por el $\mathrm{CN}^{24}$. El máximo órgano legislativo del país ha decidido por una holgada mayoría eximirlo del juicio de impeachment en una decisión cuya singularidad merecerá un comentario posterior.

3. EL JUICIO DE IMPEACHMENT EN LA CONSTITUCIÓN FEDERAL BRASILEÑA DE 1988: CARACTERÍSTICAS ESENCIALES Y FINALIDAD

La Constitución Federal de 1988 (en adelante, CF) regula el impeachment detalladamente, en los artículos 85 y 86, por lo que coincide con su condición de constitución analítica. Esta decisión expresa un claro continuismo no solo con la práctica de los vecinos de Brasil, sino también con su propia historia constitucional, ya que este tipo de juicio político ha formado parte de cuantas constituciones ha tenido el país desde 1891. Como curiosidad histórica, hay que decir que nació con una estima doctrinal muy escasa ${ }^{25}$.

La doctrina brasileña especializada, en la que destaca el profesor Brossard, define el impeachment como aquel proceso que: a) tiene características políticas; b) se origina por causas políticas; c) busca resultados políticos; d) se instaura bajo consideraciones de orden político; e) es juzgado siguiendo criterios políticos; f) sin por ello excluir, obvio es decirlo, la adopción previa de criterios jurídicos ${ }^{26}$. Pontes de Miranda, por su parte, hace énfasis en la correlación existente entre la magnitud de los poderes y competencias que acumula el Presidente de la República y la responsabilidad derivada de los mismos, de tal forma que el incumplimiento u omisión en el ejercicio de sus funciones posibilitaría su cese ${ }^{27}$.

Se está, en definitiva, ante un proceso de naturaleza y contornos políticos -con los matices que luego se verán- cuya finalidad es dilucidar y penalizar, llegado el caso, conductas antiéticas de carácter grave mediante la instauración de un proceso en sede parlamentaria dirigido contra altos cargos del Estado. El objetivo, fácilmente deducible, es remover de su cargo e inhabilitar a altos dignatarios del Estado para el desempeño de cargo público por un espacio de tiempo determinado y con independencia de posibles sanciones penales adicionales. En la actualidad, este instituto, una vez despojado de su

24 Datos disponibles en: https://www.nytimes.com/es/2017/06/27/acusado-de-corrupcionel-futuro-de-michel-temer-esta-en-manos-del-congreso-de-brasil/ (Consultado el 10 de agosto de 2017).

25 Barbosa, R. Ruínas de um governo. Rio de Janeiro: Guanabara, 1931, 97. Un breve recorrido histórico del instituto del impeachment puede verse en RESENDE DE BARROS, S. Impeachment: peça de museu? En Revista Brasileira de Direito, IMED. Vol. 7, n. ${ }^{\circ}$ 1, 2011, $126 \mathrm{ss}$.

26 Brossard de Souza Pinto, P. O impeachment: aspectos da responsabilidade política do Presidente da República. São Paulo: Imprenta, 1992, 71.

27 Cavalcanti Pontes de Miranda, F. Comentários à Constituição da República dos E.U. do Brasil. Vol. 1. São Paulo: Revista dos Tribunais, 1976, 592. 
origen histórico de corte monárquico, se reviste de una evidente naturaleza republicana que busca el perfeccionamiento de las instituciones ${ }^{28}$.

No hay manera de negar la extrañeza que puede provocar el hacer del poder legislativo un tribunal especial encargado de juzgar un delito de responsabilidad $^{29}$. Se trata de una circunstancia calificable de competencia atípica en atención a la división de funciones estatales establecidas en la República federal brasileña y de acuerdo a la lógica funcional propia del Estado democrático. Tal afirmación no excluye que esta "rareza" tenga lugar dentro de los cuadrantes en que se mueve la función política del Estado. En este sentido, los elementos cruciales que dotan de legitimidad material al proceso son los siguientes: a) la eliminación de cualquier posible arbitrariedad y discrecionalidad en la concreción de las áreas de incertidumbre propias de la tipificación de los delitos de responsabilidad ${ }^{30} ;$ y b) la comprobación fehaciente del dolo en la comisión de los delitos por parte del Presidente. A sensu contrario, quedan fuera de la órbita del juicio de impeachment la incompetencia o falta de adecuación en el ejercicio de las funciones ${ }^{31}$.

Dicho en términos prosaicos, el Presidente de la República no puede ser apartado por un mero juicio de oportunidad política o conveniencia del Parlamento, como en el caso de los sistemas parlamentarios; tan solo cabe su remoción ante la comisión de infracciones previstas normativamente y demostradas de acuerdo a los parámetros del debido proceso legal. Haciendo propias las palabras de Alves Pinto Serrano, "[e]n el presidencialismo, el Presidente se sujeta a un específico proceso político-administrativo de responsabilidad"32.

Debe advertirse, aun a riesgo de resultar ocioso, que la correcta definición de los requisitos jurídicos del proceso de impeachment y la reducción de las posibles áreas grises a su mínima expresión precisa, lógicamente, de la lectura sistemática de los preceptos constitucionales que guardan relación con los artículos 85 y $86 \mathrm{CF}^{33}$. El primero de los dispositivos constitucionales presenta la siguiente redacción:

Constituyen delitos de responsabilidad los actos del Presidente de la República que atenten contra la Constitución Federal y especialmente contra: I) la existen-

28 Resende De BARRos. Impeachment: peça de museu?, cit., 114.

29 Afonso da Silva, J.A. Curso de direito constitucional positivo. 25. a ed. São Paulo: Malheiros, 2005, 550.

30 Alves Pinto Serrano, P. E. Dos requisitos jurídicos para a instauração do processo de impeachment do Presidente da República. En Revista de Investigações Constitucionais. Vol. 2, n. ${ }^{\circ} 2,2015,202$.

31 Ibíd., 204.

32 Ibíd.

33 Ibíd., 190; BandeIra de Mello, C. A. Curso de direito administrativo. São Paulo: Malheiros, 2009, 951. 
cia de la Unión; iI) el libre ejercicio del Poder Legislativo, del Poder Judicial, del Ministerio Público y de los Poderes constitucionales de las unidades de la Federación; III) El ejercicio de los derechos políticos, individuales y sociales; Iv) la seguridad interna del país; v) la probidad en la Administración; vI) la ley presupuestaria; vII) el cumplimiento de las leyes y de las decisiones judiciales. (Traducción propia).

En la medida en que el sistema de gobierno brasileño es presidencialista, cabe exigir la responsabilidad política del Presidente por una doble vía: en su condición de Jefe de Estado (art. 85, I-IV) o en su posición de Jefe de Gobierno (art. $85 \mathrm{~V}$-VII). En una primera lectura, se percibe claramente que los incisos I, II y VII del artículo 85 tienen como objetivo principal la protección de la integridad nacional y de los diferentes poderes en que se organizan el Estado federal brasileño y el resto de instituciones constitucionales investidas de poder. La validez de esta afirmación se apoya en otro dispositivo constitucional, el artículo 78, que exige como acto previo a la asunción efectiva al poder la prestación de consentimiento de Presidente y Vicepresidente en el sentido anterior ${ }^{34}$.

El inciso III, por su parte, supone una garantía adicional a los ya de por sí exhaustivos medios de protección con que cuentan los derechos fundamentales en la Constitución brasileña. Valga recordar, a título meramente ilustrativo, su condición de cláusulas pétreas establecidas en el artículo 60 , § $4 \mathrm{CF}^{35}$. El inciso IV se refiere a la responsabilidad del Presidente en su condición de Jefe de Estado ${ }^{36}$. El inciso v, en buena lógica con la condición del Presidente de Jefe de la Administración Pública, exige la sujeción de este a los principios rectores de su funcionamiento.

La adecuada comprensión del inciso vi requiere de su interpretación en conexión con el artículo 167, que trata del presupuesto público y que tipifica los supuestos de responsabilidad en aquellos casos en que la ejecución de las inversiones vaya más allá de un ejercicio financiero y además no se hayan incluido previamente en el plano plurianual o ley que autorice dicha inclusión.

El parágrafo único del artículo 85, por último, instituye una reserva de competencia exclusiva en favor de la Unión, de tal forma que tan solo a ella le compete legislar respecto a la tipificación de los crímenes de responsabilidad y su iter procesal correspondiente. Esta ley es la n. ${ }^{\circ} 1.079 / 1950$, recepcionada

34 Streck, L. et al. Seção III. Da responsabilidade do Presidente da República. En Gomes Canotilho, J. J. Comentários à Constituição. São Paulo: Saraiva, 2013, 1286.

35 Almagro Castro, D. La problemática del poder de reforma constitucional en Brasil: cláusulas pétreas, control judicial de enmiendas constitucionales y principio democrático. En Revista de Derecho Político. N. ${ }^{\circ}$ 94, 2015, 265 ss.

36 El conjunto de crímenes de responsabilidad establecidos en los incisos I a IV del artículo 85 son definidos por José Afonso da Silva como infracciones políticas. DA Silva. Curso de direito constitucional positivo, cit., 551. 
parcialmente por la Constitución a través de la jurisprudencia del STF con ocasión del impeachment del presidente Fernando Collor de Melo $^{37}$. No es vano recordar que el legislador, casi treinta años después, continúa sin cumplir el mandato constitucional de proferir ley especial al respecto, conducta calificable como una omisión a sus funciones en atención a la importancia intrínseca del impeachment en la lógica funcional del sistema político.

El ámbito en que se desarrolla el juicio de impeachment es, de acuerdo con la jurisprudencia del STF, el político-administrativo. Esta circunstancia no lo exime del cumplimiento de las garantías propias del derecho administrativo sancionador y de determinados elementos del proceso judicial propiamente dicho $^{38}$.

En sentido concurrente se posiciona el profesor Barroso, para quien es innegable la dimensión política del juicio de impeachment por dos motivos específicos: a) la imposibilidad por parte del poder judicial de revisar el mérito del fallo de las cámaras, y b) que la decisión no debe cumplir con los rigores de objetividad y motivación impuestos a los pronunciamientos judiciales propios del artículo 93, IX CF. El matiz radica, en opinión del ilustre magistrado del STF, en la competencia que el alto tribunal tiene de revisar tanto que la competencia constitucional se ha desarrollado dentro de sus límites legítimos como la no violación de derechos subjetivos ${ }^{39}$. Dicho en otros términos, el sistema de garantías inherente al derecho penal y el proceso penal deben ser aplicables, en lo que resulte factible, al proceso y enjuiciamiento de los delitos de responsabilidad, en especial la regla de la modalidad dolosa. Excepcionalmente -siempre que exista disposición legal expresa- se admitirá la modalidad estrictamente culposa. Resultan igualmente aplicables el principio in dubio pro reo y la interpretación restrictiva, garantías clásicas del derecho penal ${ }^{40}$.

En este sentido deben entenderse las garantías establecidas en el artículo 38 de la Ley 1.079/1950, que determina que en el enjuiciamiento del Presidente de la República serán subsidiarios al articulado de la ley no solo los reglamentos internos de las cámaras que conforman el CN -Cámara de los Diputados y Senado Federal- sino también el Código de Proceso Penal ${ }^{41}$.

37 STF. MS n. ${ }^{\circ}$ 21.564/DF, Rel. para o acórdão Min. C. Velloso, juzgado el 23 de septiembre de 1992.

38 STF. IF 590 Qo/CEF, Rel. Ministro Celso de Mello, juzgado el 17 de septiembre de 1998.

39 BARROSO, L. R. Impeachment - crime de responsabilidade - exoneração do cargo. En Revista de Direito Administrativo. N. . 212, 1998, 162.

40 Alves Pinto Serrano. Dos requisitos jurídicos para a instauração do processo de impeachment do Presidente da República, cit., 206.

41 Art. 38 de la Ley 1.079/50: "No processo e julgamento do Presidente da República e dos Ministros de Estado, serão subsidiários desta lei, naquilo em que lhes forem aplicáveis, assim os regimentos internos da Câmara dos Deputados e do Senado Federal, como o Código de Processo Penal". 
Las conductas que posibilitan la apertura del juicio de impeachment stricto sensu son las propias de los delitos de responsabilidad, es decir, aquellas que pueden ser realizadas por determinados agentes políticos en razón de los cargos públicos que ocupan y que, de acuerdo a lo establecido en el parágrafo único del artículo 85, son objeto de desarrollo en una ley especial que establecerá las normas del proceso y el propio enjuiciamiento ${ }^{42}$. Se habla, como ya se anticipara, de la Ley 1.079/50 (Parte Segunda, arts. 14 a 38).

La CF también prevé en el artículo 86 § 4 la posibilidad de abrir un proceso de destitución del Presidente por la comisión de delitos comunes, proceso que, si bien es cierto comparte determinadas pautas procesales con el juicio de impeachment, no debe confundirse con este. El dispositivo constitucional incluye aquellos ilícitos regulados por la ley penal, con la particularidad de haber sido cometidos por el Jefe de Estado de la República durante el ejercicio de su mandato ${ }^{43}$. La expresión "delito común" es usada en el contexto constitucional con el ánimo de establecer una diferenciación con los conocidos -impropiamente- como crímenes de responsabilidad, objeto de sanción política y que comprenden todo y cualquier delito ${ }^{44}$. Dicho en términos directos: el juicio de impeachment precisa, ex ante, de la comisión del delito durante el ejercicio del mandato y de la culpabilidad estricta, no bastando la mera omisión ${ }^{45}$.

Este aspecto es de vital importancia para evitar posibles usos espurios del texto constitucional. Valga como ejemplo el caso de Paraguay, en el que la oposición reformó la Constitución de manera que la caída del Presidente de la República resultase legítima tan solo por el hecho de alcanzar la mayoría cualificada de dos tercios y sin necesidad de probar debidamente los hechos imputados al Jefe del Ejecutivo. Una actitud, difícil negarlo, bien parecida a un golpe de Estado $^{46}$.

Cierra la regulación constitucional del impeachment al Presidente de la República -el único objeto de análisis aquí- el ya citado artículo $86 \mathrm{CF}$, que a la letra dispone:

42 BARroso. Impeachment - crime de responsabilidade - exoneração do cargo, cit., 163; StReCK et al. Seção III. Da responsabilidade do Presidente da República, cit., 1289.

43 Art. 86, § 4. § 4": "O Presidente da República, na vigência de seu mandato, não pode ser responsabilizado por atos estranhos ao exercício de suas funções".

44 Brossard. O impeachment: aspectos da responsabilidade política do Presidente da República, cit., 71.

45 Alves Pinto Serrano, P. E. Dos requisitos jurídicos para a instauração do processo de impeachment do Presidente da República. En Revista de Investigações Constitucionais. Vol. 2, n. ${ }^{\circ} 2$, 2015, 207; STRECK, L. Entrevista . Disponible en: http://zh.clicrbs.com.br/rs/noticias/proa/ noticia/2015/02/lenio-streck-nao-ha-nenhum-elemento-objetivo-para-impeachment-4708988. html (Consultado el 10 de agosto de 2017).

46 Piñero, M. T. Democracia y neoliberalismo en la región: Paraguay y el golpe. En Estudios. N. ${ }^{\circ}$ 31, 2014, 113. 
Admitida la acusación contra el Presidente de la República, por dos tercios de la Cámara de los Diputados, será objeto de enjuiciamiento ante el Tribunal Supremo Federal, en las infracciones comunes, o ante el Senado Federal, en los crímenes de responsabilidad. $§ 1 .^{\circ}$ El Presidente será suspendido de sus funciones: I. En las infracciones penales comunes, si la queja o denuncia fuese recibida por el Supremo Tribunal Federal. § 2. ${ }^{\circ} \mathrm{Si}$, transcurrido el plazo de ciento ochenta días, no hubiere acabado el juicio, cesará el alejamiento del Presidente, sin perjuicio de regular la continuación del proceso. § 3..$^{\circ}$ Mientras no sobreviniese sentencia condenatoria, en las infracciones comunes, el Presidente no estará sujeto a prisión. $\S 4 .^{\circ}$ El Presidente de la República, en la vigencia de su mandato, no podrá ser responsabilizado por actos extraños al ejercicio de su mandato. (Traducción propia).

De nuevo, y como puede observarse fácilmente, se está ante una regulación ciertamente detallada de las diferentes fases que componen el juicio de impeachment. La primera versa sobre el juicio de admisibilidad, en manos de la CD y de acuerdo al contenido del artículo 51, I CF ${ }^{47}$. Los pormenores del procedimiento de presentación de la denuncia están establecidos en el "Regimento Interno da Câmara dos Deputados" (en adelante, RICD) ${ }^{48}$ y los artículos 14 a 18 de la Ley 1.079/50. La presentación de la demanda, prerrogativa de cualquier ciudadano según lo dispuesto en el artículo 14 del antedicho cuerpo legal, se realiza ante el presidente de la Cámara, que examinará su contenido y evaluará la pertinencia o no de los argumentos presentados; es decir, la tipicidad de la conducta y la consistencia de los fundamentos de derecho ${ }^{49}$. Contra la resolución del presidente cabe recurso de cualquier parlamentario ante el pleno de la Cámara.

Una vez admitida a trámite la petición, se procederá a su votación de acuerdo a la mayoría híper reforzada establecida en el primer párrafo del artículo $86 \mathrm{CF}$ : dos tercios de sus miembros en una votación de carácter nominal. Estamos, obvio es decirlo, ante una exigencia plenamente coherente con la naturaleza, relevancia y finalidad del instituto jurídico en cuestión y que, dicho sea de paso, fue incorporada por vez primera en la Constitución de 1967-1969.

Obtenida la mayoría exigida, el texto constitucional establece dos órganos de enjuiciamiento diferentes en función del supuesto de hecho de que se trate. Para las infracciones comunes, el órgano competente será el STF; en caso de crímenes de responsabilidad stricto sensu, el órgano enjuiciador

47 Art. 51: "Compete privativamente à Câmara dos Deputados: I - Autorizar, por dois terços de seus membros, a instauração de processo contra o Presidente e o Vice-Presidente da República e os Ministros de Estado".

48 Texto disponible en: http://www2.camara.leg.br/atividade legislativa/legislação/ regimento-interno-da-camara-dosdeputados/RICD\%20atualizado\%20ate\%20RICD\%2020-2016. pdf (Consultado el 10 de agosto de 2017).

49 Cfr. arts. 14-18 RICD. 
será el Senado Federal ${ }^{50}$. La consecuencia inmediata de la recepción del pedido de impeachment por parte de cualquiera de estos dos órganos es la suspensión del Presidente de la República en el ejercicio de sus funciones por tiempo de ciento ochenta días (art. 86, § $1 \mathrm{CF}$ ). Es este un plazo de carácter preclusivo, lo cual implica que el Presidente retomará sus funciones con independencia de la continuidad del proceso al cumplirse dicho plazo (art. 86, § 2). Esta regulación es, dígase de pasada, más exhaustiva que la que establecía la Constitución de 1967, la cual limitaba el plazo temporal a sesenta días transcurridos los cuales la causa era archivada.

La pertinencia de apartar al Presidente del ejercicio de sus funciones es cuestión polémica en la doctrina brasileña. Ya con motivo de su inclusión en la Constitución de 1891, Cavalcante Barbalho Uchoa hacía referencia a la improcedencia de equiparar la principal magistratura del país con cualquier funcionario administrativo, así como la más que probable inestabilidad derivada de reemplazar al gobierno en un momento de tamaña relevancia ${ }^{51}$. Más allá de esta sugerente opinión, la realidad es que la norma del alejamiento persiste bajo el argumento de evitar posibles influencias y presiones del Presidente de la República sobre los encargados de enjuiciar su actuación; es decir, se pretende impedir mayores peligros que los derivados de su sustitución temporal ${ }^{52}$.

El § 3. . establece un conjunto de garantías propias del proceso penal. La primera, derivada de la presunción de inocencia, condiciona el ingreso en prisión del Presidente a la existencia de sentencia condenatoria emitida por el STF. Queda descartada, en consecuencia, cualquier posibilidad de prisión preventiva o temporal. El $\S 4 .^{\circ}$ del artículo $86 \mathrm{CF}$ dispone una suerte de inmunidad temporal de la responsabilidad penal del Presidente, al condicionarla a que el delito en cuestión lo haya sido durante y en razón de su mandato ${ }^{53}$.

En el caso de una hipotética reelección del mandatario durante la fase de enjuiciamiento no se produciría la extensión temporal de la responsabilidad penal. Esta circunstancia encuentra apoyo en la interpretación literal de los artículos 28, 29 incisos I y II, y $77 \mathrm{CF}$, que establece un periodo determinado de cuatro años de mandato incluyendo su inicio: el $1 .^{\circ}$ de enero del año siguiente a su elección.

En el juicio de impeachment-circunscrito a los delitos de responsabilidady como tal sometido a escrutinio del Senado Federal, la mayoría exigida es

50 Art. 52: "Compete privativamente ao Senado Federal: processar e julgar o Presidente e o Vice-Presidente da República nos crimes de responsabilidade, bem como os Ministros de Estado e os Comandantes da Marinha, do Exército e da Aeronáutica nos crimes da mesma natureza conexos com aqueles".

51 Cavalcante Barbalho Uchoa, J. Constituição Federal Brasileira: comentários por João Barbalho. Brasília: Senado Federal, Secretaria de Documentação e Informação, 1992, 215.

52 RESENDE DE BARRos. Impeachment: peça de museu?, cit., 131.

53 Streck et al. Seção III. Da responsabilidade do Presidente da República, cit., 1288. 
idéntica a la de la $\mathrm{CD}$, es decir, dos tercios en votación pública nominal. Con anterioridad a la votación, el Presidente podrá ejercer las garantías inherentes al derecho de amplia defensa y el principio de contradicción, de acuerdo al artículo 5. ${ }^{\circ}, \mathrm{LV}$ CF. Una prerrogativa de uso en ambas cámaras legislativas.

En caso de superar los dos tercios de votos afirmativos en el Senado, la pena decretada mediante resolución formal es la establecida en el parágrafo único del artículo 52 CF: ocho años de inhabilitación para el ejercicio de cualquier cargo público sin excluir por ello posibles sanciones judiciales ${ }^{54}$. Debe concluirse este apartado diciendo que la petición de renuncia del Presidente no extinguirá el procedimiento, de acuerdo con la jurisprudencia del STF establecida con ocasión del proceso de impeachment al expresidente Fernando Collor de Mello ${ }^{55}$.

Hasta aquí el iter procesal del juicio de impeachment por crímenes de responsabilidad. Es momento de retomar el análisis sobre los elementos básicos del proceso de petición de responsabilidades derivado de la comisión de delitos comunes. El punto de partida es claro: no cabe calificar este proceso como de impeachment puesto que su resultado final depende del enjuiciamiento de un órgano de naturaleza estrictamente judicial -el STF-, cuya actuación se mide y responde exclusivamente a parámetros jurídicos.

Este proceso se encuentra dividido igualmente en dos fases: el juicio de admisibilidad ante la CD y la fase de procesamiento y enjuiciamiento. Es en esta última donde comienzan las diferencias con el juicio de impeachment. Como ya se ha visto, el artículo $86 \mathrm{CF}$ establece que los procesos derivados de la comisión de delitos comunes serán juzgados ante el STF, de acuerdo con la condición de aforado del Presidente establecida en el artículo 102, I, $\mathrm{b}^{56}$. En este punto ha de matizarse que el aforo privilegiado cesará con el fin del mandato, aun cuando la infracción fuese cometida durante su vigencia ${ }^{57}$.

El procedimiento se inicia, de acuerdo al artículo 14 de la Ley 1.097/50, mediante denuncia presentada por cualquier ciudadano. Una vez nombrado el ministro encargado de verificar la pertinencia en derecho de la denuncia, la hará llegar a manos del Procurador General de la República, quien repetirá el análisis de idoneidad de la demanda y, llegado el caso, la enviará a la CD bajo el parámetro homólogo de los crímenes de responsabilidad: su aprobación por mayoría de dos tercios en votación pública nominal. De vuelta al STF, el

54 Art. 52, pará. único: "Nos casos previstos nos incisos I e II, funcionará como Presidente o do Supremo Tribunal Federal, limitando-se a condenação, que somente será proferida por dois terços dos votos do Senado Federal, à perda do cargo, com inabilitação, por oito anos, para o exercício de função pública, sem prejuízo das demais sanções judiciais cabíveis".

55 BARRoso. Impeachment - crime de responsabilidade - exoneração do cargo, cit., 167.

56 Art. 102: "Compete ao Supremo Tribunal Federal, precipuamente, a guarda da Constituição, cabendo-lhe: I.- processar e julgar, originariamente: [...] b) nas infrações penais comuns, o Presidente da República...".

57 Cfr. Acción Directa de Inconstitucionalidad (ADI) n. ${ }^{\circ} 2797$. 
ministro relator convoca al Presidente de la República para que este ejerza su derecho de defensa. Por último, la demanda es elevada al pleno del STF, a quien le corresponde emitir sentencia. Queda igualmente excluida la prisión preventiva en todas las diferentes fases del procedimiento.

Volviendo al análisis de la naturaleza y características del juicio de impeachment stricto sensu, este presenta conclusiones necesitadas de comentario. La primera es que, aun tratándose de un juicio de naturaleza política, no puede prescindir por completo de las características propias del proceso penal. Además, a la presencia de las garantías propias del proceso penal ha de sumársele la comprobación de actitud dolosa por parte del Presidente de la República o la asunción del riesgo de producirlo. La responsabilidad derivada de las conductas culposas, imprudentes, negligentes o incompetentes solo podría justificarse si la Constitución lo estableciese expresamente. En consecuencia, deben ser entendidos como no recepcionados por la $\mathrm{CF}$ aquellos artículos de la Ley 1.079/50 que admiten la imputación de impeachment ante conductas estrictamente culposas.

Esta tesis -la existencia de dolo como conditio sine qua non del impeachment-arroja sospechas más que fundadas sobre la legitimidad jurídica del proceso que ha supuesto la renuncia forzada de la primera mujer presidenta de la República elegida democráticamente por 54 millones de ciudadanos. La demostración de esta afirmación -es decir, la insuficiencia de la argumentación jurídica y la existencia de factores extra jurídicos no menos relevantes como detonantes del impeachment- es el argumento principal del último apartado de este artículo.

\section{CRÓNICA DE UN IMPEACHMENT ¿LEGÍTIMO?: UNA REVISIÓN DE LOS HECHOS Y LOS ARGUMENTOS DE DERECHO SIN OLVIDAR EL PRECEDENTE COLLOR DE MELLO}

En el desarrollo del presente artículo se ha aludido ocasionalmente al otro proceso de impeachment ocurrido en Brasil desde la reinstauración de la democracia en 1988. Se alude, claro está, al caso del expresidente Collor de Mello en $1992^{[58]}$. La relativa proximidad entre ambos acontecimientos -25 años- posibilita un breve análisis comparativo con el afán de proponer algunas conclusiones sobre el funcionamiento del sistema político brasileño y su incidencia en la invocación del impeachment ${ }^{59}$.

Para comenzar por las semejanzas -anticipando desde ya que no justifican per se la utilización del impeachment-, han de resaltarse las continuas difi-

58 Un estudio detallado puede verse en Sallum Jr., B. y Stolle Paixao E Casaroes, G. $O$ impeachment do presidente Collor: a literatura e o processo. En Lua Nova. N. . 82, 2011, 163 ss.

59 Linz, J. The Perils of Presidentialism. En Journal of Democracy. Vol. 1, n. ${ }^{\circ}$ 1, 1990, 51-69. 
cultades y la relación tormentosa que ambos presidentes tuvieron con el CN durante sus mandatos. En ambos casos fueron frecuentes las alusiones de los rivales políticos y los medios de comunicación al carácter escasamente negociador del presidente Collor de Mello y la presidenta Rousseff ${ }^{60}$. Un segundo elemento común es el escaso apoyo popular que Collor y Rousseff tenían en los momentos previos al juicio de impeachment. El instituto de investigación Datafolha situaba el nivel de aceptación popular del impeachment en un 65\% de la población, frente al $30 \%$ partidario de la continuidad de Rousseff y un $5 \%$ de indecisos ${ }^{61}$. Por su parte, las tasas de rechazo popular y en favor del impeachment contra Collor se situaron en cifras próximas al $75 \%$.

El tercer elemento común hace referencia a la fragilidad de la base de apoyo político con que contaba la expresidenta Rousseff en el segundo mandato. La presencia de 28 partidos en la CD -muestra inequívoca de una alta atomización parlamentaria-, sumado a la correlación de fuerzas entre la base gubernamental y la oposición (304 diputados frente a 204 de la oposición, con 5 neutrales del "Partido Socialismo e Liberdade", en adelante PSOL) añadía un grado adicional de dificultad a la aprobación de las reformas legales y constitucionales planteadas durante la contienda electoral ${ }^{62}$. Esta mayoría parlamentaria, de por sí exigua, menguaría vertiginosamente a raíz de los primeros rumores de impeachment a inicios de $2015^{[63]}$. El repentino viraje hacia políticas de carácter liberal forzado por el PMDB -que incluía recortes sociales y debilitamiento de los sindicatos- hizo que la mayoría de los partidos de izquierda de la coalición le retirasen el apoyo en la $\mathrm{CD}^{64}$.

En el caso de Collor, la mayoría con que contaba se disolvió en escasos meses debido al centralismo del Ejecutivo y a la concentración de poderes en el campo económico. Los numerosos casos de corrupción y financiación irregular que afectaban al partido del presidente fueron la gota que colmó el vaso ${ }^{65}$.

El catálogo de semejanzas se cierra con el ambiente de pesimismo y crisis económica que atravesaba el país. En 1992, Collor heredó una situación de inflación desbocada y recesión económica que en nada contribuyó a la

60 Cfr. Sallum Jr. y Stolle Paixao E Casaroes. O impeachment do presidente Collor: a literatura e o processo, cit., 164.

61 Datos disponibles en: http://www1.folha.uol.com.br/poder/2015/12/1714709-apoioao-impeachment-de-collor-apos-pedido-ser-aceito-era-de-75.shtml (Consultado el 10 de agosto de 2017).

62 Para la composición de la CD véase: http://g1 .globo.com/politica/eleicoes/2014/novacomposicao-da-camara.html (Consultado el 10 de agosto de 2017).

63 Datos disponibles en: http://www.publico.es/internacional/vendetta-Roussefff.html (Consultado el 10 de agosto de 2017).

64 Navarro. Volantazo en Brasil, cit., 24-25.

65 Martuscelli, D. E. O PT e o impeachment de Collor. En Opinião Pública. Vol. 16, n. ${ }^{\circ} 2,2010,543-544$. 
recuperación de la estabilidad social ${ }^{66}$. Rousseff, por su parte, se encontró ante un escenario igualmente resbaladizo: inflación por encima de dos dígitos $-10,67 \%$ al final de 2015 - y el dólar cotizando en cerca de 5 reales ${ }^{67}$.

Hasta aquí las similitudes macroeconómicas, políticas y sociales que definieron cada uno de los procesos y que pueden resumirse de la siguiente forma: a) escaso carisma del mandatario; b) falta de apoyo político; c) rechazo social expreso, si bien superior en el caso de Collor, manifestado a través de la plataforma social Caras Pintadas; d) una situación de crisis económica in crescendo. A continuación se consideran las características propias del proceso de Rousseff.

La petición de apertura de impeachment -la última de una serie cercana a veinte desde su reelección, y auspiciadas mayoritariamente por miembros del PSDB- la realizaron, a comienzos de diciembre de 2015, Hélio Bicudo, fundador del PT, y los abogados Miguel Reale Junior y Janaina Paschoal, ciñéndose para ello al procedimiento establecido en el artículo 14 de la Ley $1.079 / 50$. En este punto se hace patente la primera diferencia entre ambos procesos: mientras en el caso de Collor fue la "Ordem dos Advogados do Brasil" (en adelante, OAB), de manera autónoma, quien impulsó el proceso, en el caso de Rousseff fue el PSDB quien encargó y pagó 45 mil reales a la abogada Paschoal y al letrado Reale para que redactaran un concepto, en el cual se basó posteriormente la acción de impeachment. En un ejercicio de amnesia selectiva sin precedentes, nada dirían los relatores sobre el concepto ni el propio PSDB sobre las "pedaladas fiscales" (atrasos deliberados en el pago de créditos a bancos estatales) decretadas por el sustituto de Rousseff, Michel Temer, firmante de 3 decretos similares en ausencia de la Presidenta, sin el aval necesario del CN y por valor de 10,8 billones de reales ${ }^{68}$.

El presidente de la $\mathrm{CD}$ en aquel momento era Eduardo Cunha, dirigente del PMDB y quien se convertiría en protagonista directo del proceso por motivos que merecen un sucinto comentario. Las relaciones entre el PT y Cunha se habían enturbiado de tiempo atrás, cuando el PT había votado, en la Comisión de Ética, a favor de la casación del mandato representativo del propio Cunha por su participación directa en el caso Lava-Jato. No puede descartarse, ante los múltiples precedentes de actuación irregular de Cunha, que la aceptación de la denuncia de impeachment fuese un arma arrojadiza

66 Datos disponibles en: http://almanaque.folha.uol.com.br/dinheiro90.htm (Consultado el 10 de agosto de 2017).

67 Datos disponibles en: http://agenciabrasil.ebc.com.br/economia/noticia/2016-01/ipcainflacao-oficial-fecha-2015-em-maior-alta-desde (Consultado el 10 de agosto de 2017).

68 SEMER, M. Ruptura institucional e desconstrução do modelo democrático: o papel do Judiciário. En JinkINGs et al. (eds.), Por que gritamos golpe?, cit., 108. Datos disponibles en: http://politica.estadao.com.br/noticias/geral,temer-autorizou-mesma-manobra-usada-pordilma,10000004177 (Consultado el 10 de agosto de 2017). 
para presionar al $\mathrm{PT}^{69}$. Esta hipótesis sería luego confirmada por uno de los autores del pedido de impeachment, Miguel Reale Junior, quien hablaría explícitamente de chantaje por parte de aquel ${ }^{70}$.

Se está ante el primer conflicto de intereses que siembra dudas sobre la neutralidad que debería presidir la actuación del presidente de la CD. Como argumento a fortiori, el propio Cunha, haciendo un uso espurio de sus prerrogativas, alteraría los nombres de los integrantes de la comisión de tramitación para el mismo día y hora en que iba a ser tratado su caso en la Comisión de Ética, con el fin de provocar la suspensión de su causa particular ${ }^{71}$.

El pedido de impeachment sería aprobado el 11 de abril por una comisión especial de la CD en una votación con 38 votos favorables y 27 contrarios. Y el 17 de abril sería admitida su tramitación tras una votación con 367 votos favorables y 137 contrarios. A comienzos de mayo, el presidente de la CD, Eduardo Cunha, sería relevado de sus funciones por orden del Supremo Tribunal Federal luego de ser declarado culpable de obstrucción a la justicia.

Por otra parte, es necesario resaltar que la acusación a Rousseff se basaba en el incumplimiento por parte de la Presidenta de las obligaciones fiscales establecidas en el artículo 36 de la ley presupuestaria y la ley de responsabilidad fiscal. Concretamente, se le reprochaba el haber maquillado el déficit público mediante la transferencia de cantidades procedentes del estatal Banco do Brasil (en adelante, BB) durante el año de 2015.

En octubre de 2015 Rousseff sufriría un revés institucional que daría munición adicional a la oposición. El "Tribunal de Contas da União" (en adelante, TCU) remitiría un concepto al CN reprobando las cuentas del Ejecutivo con base, precisamente, en la existencia de "pedaladas fiscales" contrarias a la ley presupuestaria y a la ley de responsabilidad fiscal.

Según el PSDB, y amparándose en el informe del TCU, la Presidenta habría cometido "pedaladas fiscales" en el marco del "Plano Safra", referido a subsidios para pequeños y medianos agricultores financiados mediante cantidades solicitadas al BB. El atraso en los pagos de las cantidades solicitadas entre enero y noviembre de 2015 generó unos intereses de 450 millones de reales.

Es de especial importancia en este punto aludir al informe emitido por la comisión de tres técnicos del Senado -a petición de la Comisión de impeachment del Senado- para determinar si había habido responsabilidad directa de Rousseff en las "pedaladas fiscales". En palabras de los técnicos,

69 Löwy, M. Da tragédia à farsa: o golpe de 2016 no Brasil. En Jinkings et al. (eds.), Por que gritamos golpe?, cit., 64; QuinalHa, R. Em nome de Deus e da família: um golpe contra a diversidade, ibíd., 131.

70 Datos disponibles en: http://congressoemfoco.uol.com.br/noticias/cunha-fezchantagem-explicita-diz-reale-junior/ (Consultado el 10 de agosto de 2017).

71 https://noticias.uol.com.br/politica/ultimas-noticias/2015/12/07/cunha-adia-instalacaoda-comissao-que-analisara-impeachment-para-terca.htm (Consultado el 10 de agosto de 2017). 
el análisis de la documentación aportada por la acusación y la defensa no permite identificar acto alguno -directo o indirecto- de la Presidenta que influyese en el atraso en los pagos. Este hecho sería usado como argumento de peso por los abogados defensores de la mandataria, quienes afirmarían que "no hay crimen sin autoría. En el crimen de responsabilidad no existe el acto por omisión"72.

La otra acusación en contra de la Presidenta se refería a la publicación de cuatro decretos de créditos suplementarios sin la correspondiente solicitud previa de autorización al CN, en contra de lo dispuesto en la propia CF. Según el informe técnico, tres de los decretos sí tuvieron consecuencias negativas para el necesario equilibrio presupuestario. El otro sería definido por los técnicos como neutral y acabaría siendo retirado, junto a otros dos, como prueba de cargo. En cuanto a la autoría, no habría duda alguna de que correspondía a la Presidenta.

¿Qué valoración jurídica merecen las "pedaladas fiscales" cometidas por la Presidenta? En el presente trabajo se considera que se está ante meras maniobras fiscales que, con independencia de la reprobación que puedan merecer, en manera alguna están contempladas en la Constitución como susceptibles de generar un crimen de responsabilidad fiscal ${ }^{73}$.

Continuando con el relato de los hechos, llama la atención la naturaleza de los "argumentos jurídicos" esgrimidos por los jueces para aprobar la petición de impeachment de la Presidenta; la gran mayoría de índole personal y tan grotescas como "por mi esposa Paula", "por mi hija que va a nacer y la sobrina Helena", "por mi familia y mi Estado", así como otras cuyo vacío discursivo provoca rubor escribir ${ }^{74}$. Este hecho resulta aún más chocante si se tiene en cuenta la no obligatoriedad legal de hacer públicas las razones de la votación.

El 12 de mayo, el Senado Federal aprobaría el inicio de la tramitación del impeachment en la cámara alta por 55 votos a favor y 22 en contra. Este hecho traería consigo la suspensión provisional de Rousseff y la asunción de Michel Temer como Presidente interino de la República. Las primeras medidas decretadas por el Presidente transitorio - para las cuales, obvio es decirlo, estaba legalmente facultado- tendrían un alto valor simbólico e ideológico: retomar la senda ultraliberal y acabar de raíz con todo vestigio de las políticas sociales de inclusión y género del gobierno Rousseff ${ }^{75}$. Valga

72 Una crónica detallada del relato de la comisión técnica puede verse en: https://brasil. elpais.com/brasil/2016/06/27/politica/1467040634_118457.html (Consultado el 10 de agosto de 2017).

73 Gómes, C. Por que o golpe acontece? En Jinkings et al. (eds.), Por que gritamos golpe?, cit., 41.

74 Quinalha, R. Em nome de Deus e da família: um golpe contra a diversidade. En JiNKINGS et al. (eds.), Por que gritamos golpe?, cit., 132.

75 Jinkings, I. et al. Por que gritamos golpe?, cit. 
como muestra la extinción del "Ministério da Mulher, Igualdade Racial e Direitos Humanos" y la disolución de la Secretaría de Derechos Humanos en la estructura del Ministerio de Justicia. También desaparecería el Ministerio de Cultura. Con todo, llama aún más la atención la nominación exclusiva para los principales puestos y escalafones ministeriales de hombres blancos, y la correlativa desaparición de la población negra e indígena de puestos de responsabilidad gubernamental y con visibilidad social ${ }^{76}$.

Las medidas de tipo presupuestario serían aún más contundentes. El nuevo ministro de Hacienda, Henrique Meirelles, anunciaría una propuesta de enmienda a la Constitución (PEC) -hoy día aprobada definitivamente- con el objetivo de limitar el gasto público al incremento de la inflación durante un periodo de veinte años. Este hecho supone la abierta contravención de la naturaleza social de la Constitución de 1988 con el débil argumento de contener el derroche presupuestario de los gobiernos del PT ${ }^{77}$. El resto de la historia ya es sobradamente conocido: el 31 de agosto el Senado Federal decidiría por 61 votos favorables y 20 en contra la destitución definitiva de Rousseff. En octubre de 2016, el magistrado del STF, Teori Zavascki, negaría el pedido de la mandataria para anular el impeachment con el argumento de no haberse demostrado por la defensa ningún "riesgo para las instituciones republicanas, el Estado democrático de derecho o el orden constitucional". Se consumaba así, de forma definitiva, la renuncia forzada de la primera Presidenta de Brasil por la comisión, en el peor de los casos, de errores de gestión que aun siendo graves no constituyen un delito de responsabilidad.

No debe dejarse pasar la ocasión de comentar la situación judicial de los representantes del CN que decidieron apartar a una Presidenta de la República elegida democráticamente por 54 millones de ciudadanos. Si se dan por válidos los datos de la oNG anticorrupción Transparencia Brasil, el 59\% de los miembros del poder legislativo brasileño tenía causas pendientes con la justicia por diferentes motivos que conviene citar. De los 513 diputados, la nada despreciable cifra de 303 tenía, el día de la votación, procesos pendientes o condenas judiciales o expedientes en tribunales de cuentas por delitos como lavado de dinero, compra de votos y hasta homicidio culposo. $\mathrm{Y}$ en el caso de los senadores, 49 de 81 tenían asuntos pendientes relacionados con lavado de dinero y otros delitos de corrupción ${ }^{78}$. La contundencia de estos datos -con el respeto debido a la presunción de inocencia- permite poner en tela de juicio la legitimidad moral de los representantes públicos encargados

76 RiBEIRO, D. Avalanche de retrocessos: uma perspectiva feminista negra sobre o impeachment. En Jinkings et al. Por que gritamos golpe?, cit., 127.

77 Cfr. Singer, A. Por uma frente ampla, democrática e republicana. En Jinkings et al. (eds.), Por que gritamos golpe, cit., 152.

78 Datos disponibles en: http://www.bbc.com/mundo/noticias/2016/04/160415_brasil_congreso_juicio_politico_dilma_Roussefff_mr. (Consultado el 10 de agosto de 2017); RoDRíGUES, F. Senado Capivara. En Caros Amigos. N. ${ }^{\circ}$ 230, 2016, 35-38. 
de decidir sobre la continuidad o destitución de la primera Presidenta de la República, Dilma Rousseff.

Debe concluirse el presente artículo realizando una sucinta reflexión sobre el acontecimiento anunciado al final de la introducción: la votación sobre la apertura de proceso criminal contra el presidente Michel Temer. En párrafos precedentes se aludió a la situación procesal del Jefe del Ejecutivo, sobre el que recaían numerosas sospechas de corrupción pasiva. Las investigaciones preliminares realizadas por la Policía Federal y la Fiscalía derivaron el día 26 de junio de 2017 en la formalización, por el Procurador General de la República, Rodrigo Janot, de una denuncia por delito de corrupción pasiva. Un hecho, debe decirse, sin precedentes en la historia constitucional brasileña.

Tras el informe de la "Comissão de Constituição e Justiça", el asunto se trasladaría a la $\mathrm{CD}$, a quien le compete decidir sobre la apertura o archivo del proceso de impeachment, exigiéndose para ello la mayoría de dos tercios de votos afirmativos. En este caso, la votación sería de 263 votos en contra de la apertura, 227 a favor, 2 abstenciones y 19 ausencias. Unos números relativamente lejanos de los 342 votos necesarios para la apertura formal de proceso penal ante el $\mathrm{STF}^{79}$.

Llama poderosamente la atención la diferencia de criterio del CD en el resultado de la votación si se atiende a la contundencia de las pruebas esgrimidas en uno y otro caso. En primer lugar, las consideraciones sobre la legitimidad en el origen de la denuncia son bien diferentes en uno y otro caso; en el supuesto de Temer, la denuncia proviene del Procurador General de la República. En el caso de Rousseff, la denuncia final procedió de tres abogados contratados por el PSDB y que afirmaron finalmente haber cobrado una suma de dinero y haber sido objeto de presiones en tal sentido.

La diferencia en los elementos de prueba en uno y otro caso también merece ser comentada. En el caso de Rousseff, la Policía Federal no encontró prueba alguna que la implicara en la comisión de delitos de responsabilidad. Ni tan siquiera la Comisión técnica del Senado fue unánime en sus conclusiones sobre el reproche legal que merecían las "pedaladas fiscales". Por el contrario, en el caso de Temer, la PF acabaría corroborando la validez de las escuchas telefónicas en las que el propio Temer autorizaba al empresario Joesley Batista a sobornar a Eduardo Cunha y al lobista Lucio Funaro con el objetivo de evitar delaciones por parte de ambos en el marco del caso Lava $J a t o^{80}$. Se está ante una prueba contundente sobre la existencia de un delito de corrupción pasiva públicamente conocido por la sociedad civil. Por si ello no resultase suficiente, el entonces vicepresidente Temer firmó en 2015

79 Datos disponibles en: https://placar.uol.com.br/votacao-denuncia-temer/plenariocamara (Consultado el 10 de agosto de 2017).

80 Datos disponibles en https://brasil.elpais.com/brasil/2017/06/27/politica/1498518532_904635.html (Consultado el 10 de agosto de 2017). 
tres decretos de la misma naturaleza que los de la presidenta Rousseff, por valor de 10,87 billones de reales; conducta que, no sobra recordar, era el elemento probatorio central en que se basaba la denuncia de impeachment contra aquella.

Ni la denuncia del Procurador General de la República, ni la existencia de pruebas contundentes contra Temer validadas por la PF, ni la firma de tres decretos para la transferencia de créditos públicos -las "pedaladas fiscales"- por parte de Temer en 2015 han merecido el reproche inequívoco de la CD y la continuación del proceso de impeachment. La opinión pública respecto a la figura de Michel Temer no contribuye en modo alguno a la recuperación de la normalidad política en el país: la aprobación popular del Presidente está en un misérrimo $7 \%$, el $76 \%$ de la ciudadanía considera que debería renunciar, el $81 \%$ está a favor del impeachment y el $83 \%$ considera que deberían convocarse elecciones directas ${ }^{81}$.

La pregunta, en consecuencia, resulta obvia: ¿por qué continúa Temer al frente del Ejecutivo? La hipótesis que acá se plantea, y que se viene sustentando desde el inicio del artículo, es la siguiente: el presidente Temer no ha caído todavía debido a la necesidad de parte de la CD y buena parte del empresariado envuelto en el caso Lava Jato de consolidar las medidas aprobadas en la inefable PEC 241, verdadero objetivo tras el golpe de Estado encubierto que, paralelamente, ha puesto de manifiesto la fragilidad y el insostenible grado de polarización de las instituciones democráticas brasileñas.

\section{CONCLUSIONES}

La destitución forzada de la presidenta de Brasil Dilma Rousseff, por la vía del mecanismo del impeachment, está lejos de poder considerarse un juicio político rodeado de las garantías jurídicas inherentes a un proceso de semejante importancia y consecuencias para el normal funcionamiento de las instituciones. Ya desde los inicios de la campaña político-mediática orquestada por el partido derrotado en las elecciones de 2014, el PSDB, con la ayuda de sus medios afines, se pondría de manifiesto que la reivindicación principal nada tenía que ver con la búsqueda de la probidad en las instituciones políticas. Dicho de otra forma: la salida de Dilma Rousseff de la Presidencia de la República implicaría la tan necesaria regeneración moral e institucional del país y sus instituciones.

Como se ha tenido ocasión de argumentar, la legitimidad del impeachment descansa en buena medida en la comprobación, más allá de toda duda razonable, de la existencia de dolo o de la decidida voluntad de generarlo en el marco de las conductas sometidas a enjuiciamiento. Dicha existencia,

81 Datos disponibles en: http://www1.folha.uol.com.br/colunas/pablo-ortellado/ 2017/07/1898291-por-que-temer-nao-cai.shtml (Consultado el 11 de agosto de 2017). 
si se atiende al análisis de los técnicos del Senado Federal, estuvo muy lejos de poder ser probada en el caso de la presidenta Rousseff. Se está, por el contrario, ante irregularidades fiscales que en modo alguno pueden ser considerados delitos de responsabilidad stricto sensu.

Capítulo aparte merece la vacuidad de los argumentos esgrimidos por los miembros de la cámara baja y que hablan del vergonzoso desconocimiento que los ejecutores del impeachment demostraron respecto de las conductas que justifican la continuidad del procedimiento. Salvo mejor juicio, no parece que las invocaciones a Dios, la familia o la patria fuesen argumentos jurídicos de peso para deponer a la máxima responsable del poder ejecutivo. A ello hay que añadir la delicada situación procesal y penal de buena parte de los representantes públicos. Una realidad que, con el debido respeto a la presunción de inocencia, no deja de poner en cuestión la legitimidad moral de los responsables de la deposición de la Presidenta.

La recuperación moral, institucional y económica, tan defendida y prometida por los urdidores del impeachment, está muy lejos de producirse. La aprobación en tiempo récord de la PEC 241 simboliza perfectamente las verdaderas intenciones de esta farsa política: la derogación de buena parte de los derechos sociales, laborales y previsionales del funcionariado y la clase trabajadora brasileña, elemento central del pacto social de 1988 y reforzados durante los gobiernos de Rousseff.

Dicho en términos directos: la recuperación de la probidad administrativa y la contención de la corrupción institucional eran una mera excusa para legitimar un golpe de Estado encubierto que ha supuesto la renuncia forzada de la primera mujer Presidenta de la República, la cual, es de recordarse, fue democráticamente elegida por 54 millones de ciudadanos. La diferencia de tratamiento respecto al caso Temer reafirma la hipótesis acá defendida del golpe de Estado encubierto.

\section{REFERENCIAS}

Afonso da Silva, J. Curso de direito constitucional positivo. 25. a ed. São Paulo: Malheiros, 2005.

Almagro Castro, D. Los partidos políticos en la historia constitucional brasileña. En Historia Constitucional. N. ${ }^{\circ}$ 16, 2015, 251-269.

Almagro CAstro, D. La problemática del poder de reforma constitucional en Brasil: cláusulas pétreas, control judicial de enmiendas constitucionales y principio democrático. En Revista de Derecho Politico. N. ${ }^{\circ}$ 94, 2015, 255-280.

Alves, G. A PEC 241, a contrarreforma neoliberal e a tragédia de Prometeu. 2016. Disponible en: https://blogdaboitempo.com.br/2016/10/19/a-pec-241-a-contra-reforma-neoliberale-a-tragedia-de-prometeu/ (Consultado el 10 de agosto de 2017). 
Alves Pinto Serrano, P. E. Dos requisitos jurídicos para a instauração do processo de impeachment do Presidente da República. En Revista de Investigações Constitucionais. Vol. 2, n. ${ }^{\circ}$ 2, 2015, 189-230.

Bandeira De Mello, C. A. Curso de direito administrativo. São Paulo: Malheiros, 2009.

BARbosa, R. Ruínas de um governo. Rio de Janeiro: Guanabara, 1931.

BARroso, L. R. Impeachment - crime de responsabilidade - exoneração do cargo. En Revista de Direito Administrativo. N. ${ }^{\circ} 212,1998,161-174$.

Braz, M. O golpe nas ilusões democráticas e a ascensão do conservadorismo reacionário. En Serviço Sociológico de São Paulo. N. ${ }^{\circ}$ 128, 2017, 85-103.

Brossard de Souza Pinto, P. O impeachment: aspectos da responsabilidade política do Presidente da República. São Paulo: Imprenta, 1992.

Cavalcante Barbalho Uchoa, J. Constituição Federal Brasileira: comentários por João Barbalho. Brasília: Senado Federal, Secretaria de Documentação e Informação, 1992.

Cavalcanti Pontes de Miranda, F. Comentários à Constituição da República dos E.U. do Brasil. Vol. 1. São Paulo: Revista dos Tribunais, 1973.

Costa, G. O desmonte do Estado. En Jinkings, I. et al., Por que gritamos golpe? São Paulo: Boi Tempo, 2016.

De Mello Brandao Tavares, F. et al. Um golpe anunciado: Lula, Dilma e o discurso proimpeachment na Revista Veja. En Revista Pauta Geral. Estudos em Jornalismo. Vol. 3, n. $^{\circ} 2,2016,20-44$.

Floriano Ribeiro, P. El modelo de partido cartel y el sistema de partidos de Brasil. En Revista de Ciencia Política. Vol. 33, n. ${ }^{\circ}$ 3, 2013, 607-629.

Gómes, C. Por que o golpe acontece? En Jinkings, I. et al. Por que gritamos golpe? Rio de Janeiro: Boitempo, 2016, 39-42.

Goncalves de Oliveira, H. M. Retrato das manifestações de rua no processo de impeachment da presidenta Dilma Rousseff: a construção da opinião pública pela mídia privada brasileira. En Revista Pauta Geral. Estudos em Jornalismo. Vol. 3, n. . 2, 2016, 83-96.

Jinkings, I. et al. Por que gritamos golpe? Rio de Janeiro: Boitempo, 2016.

Linz, J. The Perils of Presidentialism. En Journal of Democracy. Vol. 1, n. ${ }^{\circ}$ 1, 1990, 51-69.

Löwy, M. Da tragédia à farsa: o golpe de 2016 no Brasil. En Jinkings, I. et al. Por que gritamos golpe? Rio de Janeiro: Boitempo, 2016, 61-68.

Luiz Callai, J. O que acontece no Brasil? En Revista de Didáticas Específicas. N. ${ }^{\circ}$ 14, 2016, 176-180.

Martuscelli, D. E. O PT e o impeachment de Collor. En Opinião Pública. Vol. 16, n. ${ }^{\circ} 2$, 2010, 542-568. 
Meneguelli, G. y Ferré-Pavia, C. Apología de la polémica como modalidad argumentativa: el conflicto público en Brasil en las protestas de 2015. En Revista de Estudios Culturales de la Universitat Jaume I. Vol. XvI, 2016, 57-58.

Navarro, P. A. Volantazo en Brasil. En Los Dosieres del Siglo. N. ${ }^{\circ}$ 1156, 2016, 20-27.

Nobre, M. Choque de democracia: as razoes da revolta. São Paulo: Companhia das Letras, 2013.

Paulani, L. M. Uma ponte para o abismo. En Jinkings, I. et al. (eds.), Por que gritamos golpe? São Paulo: Boitempo, 2016, 69-75.

Piñero, M. T. Democracia y neoliberalismo en la región: Paraguay y el golpe. En Estudios. N. ${ }^{\circ} 31,2014,101-113$.

Quinalha, R. Em nome de Deus e da família: um golpe contra a diversidade. En Jinkings, I. et al. Por que gritamos golpe? Rio de Janeiro: Boitempo, 2016, 131-138.

ReIs, M. O gigante acordado. São Paulo: Leya, 2013.

Resende de Barros, S. Impeachment: peça de museu? En Revista Brasileira de Direito, IMED. Vol. 7, n. ${ }^{\circ} 1,2011,112-132$.

RIBEIRO, D. Avalanche de retrocessos: uma perspectiva feminista negra sobre o impeachment. En Jinkings, I. et al. Por que gritamos golpe? Rio de Janeiro: Boitempo, 2016, 127-131.

Ribeiro Gatto Cardoso, Y. y Bellan Rodrigues de Souza, R. Dilma, uma "presidente fora de si": o impeachment como um proceso patriarcal, sexista e midiático. En Revista Pauta Geral. Vol. 3, n. ${ }^{\circ}$ 2, 2016, 45-66.

Rodrígues, F. Senado Capivara. En Caros Amigos. N. ${ }^{\circ}$ 230, 2016, 35-38.

Sallum Jr., B. y G. Stolle Paixão y Casaroes, G. O impeachment do presidente Collor: a literatura e o processo. En Lua Nova. N. . 82, 2011, 163-200.

Semer, M. Ruptura institucional e desconstrução do modelo democrático: o papel do Judiciário. En Jinkings, I. et al. Por que gritamos golpe? Rio de Janeiro: Boitempo, 2016, 107-114.

Singer, A. Por uma frente ampla, democrática e republicana. En Jinkings, I. et al. Por que gritamos golpe? Rio de Janeiro: Boitempo, 2016, 151-156.

SouzA, J. A radiografia do golpe. São Paulo: Leya, 2016.

Streck, L. et al. Seção III. Da responsabilidade do Presidente da República. En Gomes Canotilho, J. J. Comentários à Constituição. São Paulo: Saraiva, 2013, 1285-1290.

StReck, L. Entrevista. 2015. Disponible en: http://zh.clicrbs.com.br/rs/noticias/proa/noticia/2015/02/lenio-streck-nao-ha-nenhum-elemento-objetivo-para-impeachment-4708988. html (Consultado el 10 de agosto de 2017). 